\title{
Splenic White Pulp
}

National Cancer Institute

\section{Source}

National Cancer Institute. Splenic White Pulp. NCI Thesaurus. Code C12993.

The part of the spleen that consists of nodules and other lymphatic concentrations. 